\title{
A comparison of serum zinc levels in melasma and non-melasma patients: a preliminary study of thyroid dysfunction
}

\author{
Indina Sastrini Sekarnesia ${ }^{1}$, Irma Bernadette S Sitohang ${ }^{1 凶}$, Triana Agustin ${ }^{1}$, Wismandari Wisnu², Aida SD Hoemardani ${ }^{3}$
}

${ }^{1}$ Department of Dermatology and Venereology, Faculty of Medicine, Universitas Indonesia, dr. Cipto Mangunkusumo Hospital, Jakarta, Indonesia. ${ }^{2}$ Metabolic Endocrine Division, Department of Internal Medicine, Faculty of Medicine, Universitas Indonesia, dr. Cipto Mangunkusumo Hospital, Jakarta, Indonesia. ${ }^{3}$ Department of Dermatology and Venereology, Dharmais National Cancer Hospital, Jakarta, Indonesia.

\begin{abstract}
Introduction. Melasma is an acquired hyperpigmentation disorder, clinically identified by symmetrical blackish-brown macules, especially on the facial area. Several factors are thought to play a role, including thyroid dysfunction and zinc deficiency. The aim of this study was to determine serum zinc levels in melasma and non-melasma patients with and without thyroid dysfunction.

Methods. A cross-sectional study was conducted in Jakarta in September 2019. There were 60 melasma patients and 60 nonmelasma patients. The two groups were matched for age and sex. Atomic absorption spectrophotometry was used to measure serum zinc levels. Blood laboratory tests were used to check thyroid function by measuring thyroid stimulating hormone and free T4. Statistical analysis was performed using SPSS software.

Results. The mean serum zinc level in the melasma group was $10.25 \pm 1.89 \mu \mathrm{mol} / \mathrm{l}$ and in the non-melasma group $10.29 \pm 1.46$ $\mu \mathrm{mol} / \mathrm{l}(p<0.901)$. The mean serum zinc level in melasma patients with thyroid dysfunction was $8.77 \pm 0.69 \mu \mathrm{mol} / \mathrm{l}$, in melasma patients without thyroid dysfunction $10.33 \pm 1.89 \mu \mathrm{mol} / \mathrm{l}$, in non-melasma patients with thyroid dysfunction $10.48 \pm 2.4 \mu \mathrm{mol} / \mathrm{l}$, and in non-melasma patients without thyroid dysfunction $10.27 \pm 1.4 \mu \mathrm{mol} / \mathrm{l}(p<0.184)$.

Conclusions. There was no significant difference between serum zinc levels in the melasma and non-melasma groups with and without thyroid dysfunction.
\end{abstract}

Keywords: melasma, non-melasma, serum zinc, thyroid dysfunction

Received: 23 December 2019| Returned for modification: 2 March 2020|Accepted: 26 March 2020

\section{Introduction}

Melasma is an acquired hyperpigmentation disorder caused by dysfunction of melanogenesis, appearing in the form of symmetrical blackish brown macules, especially on the facial area. Melasma causes psychosocial and emotional disorders and a significant decrease in patients' quality of life. The pathogenesis is not yet clearly known, although several factors that are thought to play a role have been identified. These factors include genetic predisposition, ultraviolet (UV) exposure, hormones, pregnancy, thyroid dysfunction, oral contraceptives, antiepileptic drugs, cosmetics and photosensitizer drugs, reactions and inflammatory processes in the skin, and events that cause emotional stress $(1,2)$. The prevalence of melasma varies between $1.5 \%$ to $33.3 \%$ depending on the demography (3). Melasma is more often found in women than men (4). Some researchers have reported an association between low serum zinc levels and various dermatological conditions, including pigmentation disorders such as melasma $(1,5)$.

Zinc deficiency is a serious health problem worldwide that affects developed and developing countries (6). The global prevalence of zinc deficiency is $17.3 \%(11-80 \%)(7,8)$. The prevalence of zinc deficiency in Indonesia is estimated at $74.3 \%$ (9). Zinc has an antioxidant and anti-inflammatory role, which can act as a regenerative agent in damaged skin (10). Zinc is also an important element in the endocrine system. Its role is very complex in thyroid function and normal thyroid homeostasis (11). Zinc is a fundamental component needed by the body for the optimal activity of many organs, such as thyroid hormone secretion (12). Zinc is an important micronutrient for human health because it has many structural and biochemical functions. Zinc deficiency can play an important role in melasma patients with thyroid dysfunction (1).

Most of the literature agrees that examining zinc levels in serum is a good indicator for assessing zinc levels in the body. This study used the atomic absorption spectrophotometry (AAS) method because it is simple, sensitive, accurate, and fast, and it can be performed in Indonesia.

\section{Methods}

This research was a cross-sectional study. Sampling was performed from the beginning to the end of September 2019 with purposive sampling in the Dermatology and Venerology Polyclinic and Internal Medicine Polyclinic of Dr. Cipto Mangunkusumo Hospital in Jakarta, Indonesia. The 120 patients included in the study were melasma and non-melasma patients selected based on inclusion criteria and exclusion criteria through patient history and physical examination. The Modified Melasma Area and Severity Index (mMASI) score assesses the area and degree of pigmentation of melasma lesions. Both parameters were assessed at four face locations: on the forehead, left and right (malar) cheeks, and $\operatorname{chin}(13,14)$.

Of the 120 patients, 60 patients were matched in the study and control groups. Patient history, physical examination, and blood tests for thyroid function and serum zinc levels were performed during the first visit. Five $\mathrm{ml}$ of blood samples were taken, comprised of $2 \mathrm{ml}$ of blood for zinc serum level and $3 \mathrm{ml}$ of blood for 
thyroid function tests (thyroid stimulating hormone (TSH) and free T4). Zinc examination was later centrifuged to extract the serum. Serum zinc levels were examined in a Southeast Asian Minister of Education Organization Regional Center for Food and $\mathrm{Nu}$ trition (SEAMEO RECFON) laboratory, Nutrition Department, and thyroid function was examined in the clinical chemistry laboratory at the Clinical Pathology Department of Dr. Cipto Mangunkusumo Hospital in Jakarta. Normal serum zinc levels are 70-131 $\mu \mathrm{g} /$ $\mathrm{dl}$ or $10.7-20 \mu \mathrm{mol} / \mathrm{l}$ with the AAS method.

The inclusion criteria in this study were female patients 18 to 59 years old. Only females were recruited in order to obtain a more homogeneous research sample. The age limit was 59 because serum zinc level declines in older age (30). The exclusion criteria in this study were consumption of zinc in the last month, consumption of steroids or other immunosuppressant drugs in the last month, being pregnant, having a history of malignancy, being in a state of fever, coughing and runny nose, having a history of chronic diarrhea, impaired kidney function, liver, digestion and heart disease, have other skin diseases (such as acne vulgaris, rosacea, psoriasis, Behçet's disease, oral aphthosis, vitiligo, leprosy, warts, cutaneous leishmaniasis, pityriasis versicolor, alopecia areata, and basal cell carcinoma), and using hormonal contraception within the last 12 months.

\section{Results}

The characteristics of the patients by group are presented in Table 1. The mean age in the case group was 48 years and in the control group 49 years. In the case group, the median duration of having melasma was 3 years, with the longest duration being 19 years and the shortest duration 1 year.

A total of 55 participants (91.7\%) in the case group and 56 participants (93.3\%) in the control group had been pregnant $(p=1)$, and as many as 16 participants (26.7\%) in the case group and 11 participants (18.3\%) in the control group had used hormonal contraception $(p<0.382)$. A history of sunscreen use was found in nine participants $(15.0 \%)$ in the case group and in eight participants (13.3\%) in the control group.

A family history of melasma was found in 30 participants $(50.0 \%)$ in the case group and in five participants $(8.3 \%)$ in the control group $(p<0.0001)$. The duration of sun or UV exposure for the median case group was 3 hours, and 2 hours for the control group $(p<0.0001)$.

In the case group, three participants $(5.0 \%)$ had subclinical hyperthyroidism, and in the control group one participant $(1.7 \%)$ had subclinical hypothyroidism, one participant (1.7\%) had hypothyroidism, one participant (1.7\%) had subclinical hyperthyroidism, and one participant (1.7\%) had hyperthyroidism.

A comparison of serum zinc levels between the melasma and non-melasma groups is presented in Table 2. A comparison of serum zinc levels between the melasma and non-melasma groups with and without thyroid dysfunction is presented in Table 3. Zinc levels in the patient group with melasma and thyroid dysfunction were lower than the other groups, at $8.77 \pm 0.69 \mu \mathrm{mol} / 1$, but the overall $p$-value was 0.184 , indicating that no significant differences were found between the groups.

Table 1 | Characteristics of sociodemographic of melasma and non-melasma patients with and without thyroid dysfunction.

\begin{tabular}{|c|c|c|c|c|}
\hline Characteristic & & $\begin{array}{l}\text { Melasma } \\
(n=60)\end{array}$ & $\begin{array}{c}\text { Non-melasma } \\
(n=60)\end{array}$ & $p$-value \\
\hline Age (yrs), median (IQR) & & $48(44-55)$ & $49(43.5-53.5)$ & $0.610 t$ \\
\hline \multirow[t]{3}{*}{ Education } & Low & $9(15.0 \%)$ & $6(10.0 \%)$ & $0.541^{*}$ \\
\hline & Medium & $37(61.7 \%)$ & $39(65.0 \%)$ & \\
\hline & High & $14(23.3 \%)$ & $15(25.0 \%)$ & \\
\hline \multirow[t]{2}{*}{ Work } & Yes & $30(50.0 \%)$ & $21(35.0 \%)$ & $0.139^{*}$ \\
\hline & No & $30(50.0 \%)$ & $39(65.0 \%)$ & \\
\hline Median UV exposure in hours (IQR) & & $3(2-4)$ & $2(1-2)$ & $<0.0001 \dagger$ \\
\hline \multirow[t]{2}{*}{ History of hormonal contraception } & Yes & $16(26.7 \%)$ & $11(18.3 \%)$ & $0.382^{*}$ \\
\hline & No & $44(73.3 \%)$ & $49(81.7 \%)$ & \\
\hline \multirow[t]{2}{*}{ Pregnancy history } & Yes & $55(91.7 \%)$ & $56(93.3 \%)$ & $1^{*}$ \\
\hline & No & $5(8.3 \%)$ & $4(6.7 \%)$ & \\
\hline \multirow[t]{2}{*}{ Sunblock } & Yes & $9(15.0 \%)$ & $8(13.3 \%)$ & $1^{\star}$ \\
\hline & No & $51(85.0 \%)$ & $52(86.7 \%)$ & \\
\hline \multirow[t]{2}{*}{ Family history of melasma } & Yes & $30(50.0 \%)$ & $5(8.3 \%)$ & $<0.0001^{\star}$ \\
\hline & No & $30(50.0 \%)$ & $55(91.7 \%)$ & \\
\hline $\begin{array}{l}\text { Mean melasma duration in years } \\
\text { (standard deviation) }\end{array}$ & & $3(3.75)$ & & \\
\hline \multirow[t]{6}{*}{ Thyroid dysfunction } & Yes & $3(5.0 \%)$ & $4(6.8 \%)$ & \\
\hline & Subclinical hypothyroid & $0(0.0 \%)$ & $1(1.7 \%)$ & \\
\hline & Hypothyroid & $0(0.0 \%)$ & $1(1.7 \%)$ & \\
\hline & Subclinical hyperthyroid & $3(5.0 \%)$ & $1(1.7 \%)$ & \\
\hline & Hyperthyroid & $0(0.0 \%)$ & $1(1.7 \%)$ & \\
\hline & No & $57(95.0 \%)$ & $56(93.3 \%)$ & \\
\hline
\end{tabular}

*using the chi-square test, tusing the Mann-Whitney test, IQR = inter quartile range, UV = ultraviolet.

Table 2 | Comparison of serum zinc levels in patients with melasma and non-melasma.

\begin{tabular}{lcc}
\hline Parameter & Serum zinc level & $p$-value* \\
\hline Melasma & & \\
Yes, $n=60$ & $10.25 \pm 1.88$ & 0.901 \\
No, $n=60$ & $10.29 \pm 1.46$ & \\
\hline *using an independent $t$-test.
\end{tabular}

Table 3 | Comparison of mean serum zinc levels in melasma and non-melasma patients with and without thyroid dysfunction.

\begin{tabular}{lcccc}
\hline \multirow{2}{*}{ Variable } & \multicolumn{2}{c}{ Thyroid dysfunction } & \multirow{2}{*}{$p$-valuet } & \multirow{2}{*}{ Overall $p$-value* } \\
\cline { 2 - 3 } Melasma & Yes & No & & \\
Yes & $n=3$ & $n=57$ & 0.164 & \\
& $8.77 \pm 0.69$ & $10.33 \pm 1.89$ & & 0.184 \\
No & $n=4$ & $n=56$ & 0.785 & \\
& $10.48 \pm 2.40$ & $10.27 \pm 1.40$ & & \\
\hline
\end{tabular}

†using an independent $t$-test, *using two-way ANOVA. 


\section{Discussion}

A previous study reported that thyroid dysfunction had a rate four times higher (58.3\%) in melasma patients than in a control group (1). Achar et al. reported that $6.4 \%$ of melasma patients had hypothyroidism (15). Subsequent studies by Rostami Mogaddam et al. reported zinc deficiency of $45.8 \%$ in melasma patients compared to $23.7 \%$ in a control group (1). In the study, $20.3 \%$ of patients with melasma had thyroid dysfunction, whereas in the control group the rate was $8.4 \%$ (15). Sinha et al. reported a correlation between zinc deficiency and hyperthyroidism (16).

The ages in both groups were matched. The mean age in the case group was 48 years and in the control group 49 years. These results are in line with a study by Sarkar et al., who reported that most melasma patients were in their third and fourth decades of life (19).

A total of 55 participants ( $91.7 \%)$ in the case group and 56 participants (93.3\%) in the control group had been pregnant $(p=1)$, and as many as 16 participants $(26.7 \%)$ in the case group and 11 participants $(18.3 \%)$ in the control group had used hormonal contraception ( $p>0.382$ ). From these results, it was concluded that there was no significant difference between the history of having been pregnant and the history of hormonal contraceptive use and the incidence of melasma. Previous studies have linked the incidence of melasma to hormonal stimulation caused by pregnancy and the use of hormonal contraception. The results of this study are in line with a study by Sanchez et al., which did not correlate pregnancy and contraceptive use with the incidence of melasma (20).

Family history was found in 30 participants $(50.0 \%)$ in the case group and five participants $(8.3 \%)$ in the control group. Family history is one of the important factors triggering the emergence of melasma, which strengthens the hypothesis of a genetic tendency for this disease. The results of this study are in line with a study by Handel et al. that found $60 \%$ of patients to have a family history of melasma (4).

The duration of sun or UV exposure for the median case group was 3 hours and for the median control group 2 hours $(p<0.0001)$. Sunlight is widely reported as a trigger factor or ballast of melasma, mainly related to its effect on melanocytes and cytokine production. Increased melanocyte proliferation and melanogenesis due to UV rays cause increased production of cytokines such as endothelin-1, interleukin-1, alpha-melanocyte stimulating hormone (a-MSH), and adrenocorticotropic hormone (ACTH) in keratinocytes (18). The results of this study are in line with a study by Achar and Rathi, which found that UV exposure exacerbates melasma (15). Constant UV exposure is a major cause of exacerbation of melasma (20). The results of this study are also in line with studies by Pichardo et al. and Sarkar et al., which found that melasma in Latino and Indian populations was related to the length of UV exposure and outdoor activities $(21,22)$.

Based on several previous studies, thyroid dysfunction has been linked to melasma. In the case group, three participants (5\%) had subclinical hyperthyroidism, and one participant $(1.7 \%)$ in the control group had subclinical hypothyroidism, one participant $(1.7 \%)$ hypothyroidism, one participant (1.7\%) subclinical hyperthyroidism, and one participant (1.7\%) hyperthyroidism. A study by Achar and Rathi reported that $6.41 \%$ of melasma patients had thyroid dysfunction (15). A study by Rostami Mogaddam et al. reported that $20.3 \%$ in the case group had thyroid dysfunction, whereas in the control group 8.4\% had thyroid dysfunction (1). A study by Huang et al. reported differences in prevalence rates in different ethnic groups and geographical areas, indicating the role of genetic and environmental factors in thyroid dysfunction, although the mechanism of this role is still not understood (23). Some of these environmental factors include alcohol consumption, smoking, iodine intake, vitamin and mineral deficiency (vitamin D and selenium), stress, infection, and use of hormonal drugs (estrogens) $(23,24)$.

Both groups had low serum zinc levels, as shown in Table 2. The results of this study are not in line with a study by Rostami Mogaddam et al., which reported $45.8 \%$ of patients in the melasma group to have low serum zinc levels compared to $23.7 \%$ of patients in the control group. Zinc appears to be effective in treating melasma due to its role as an anti-inflammatory, antioxidant, anti-peeling agent, and as one of the common ingredients of sunscreen (25). The relationship of serum zinc levels to melasma is controversial. Several studies have examined the role of zinc as an alternative to topical therapy in melasma. Sharquie et al. assessed the efficacy of topical zinc sulfate use in 14 melasma patients and obtained good results after 3 months of use (26). In contrast, Iraji et al. compared the efficacy of topical zinc sulfate therapy with $4 \%$ hydroquinone and obtained better results when using $4 \%$ hydroquinone for melasma therapy (27).

Table 3 shows that zinc levels in the patient group with melasma and thyroid dysfunction were lower than in the other groups, at $8.77 \pm 0.69 \mu \mathrm{mol} / 1$, but the overall $p$-value was 0.184 , indicating that no significant differences were found between groups. Zinc affects growth factors, endocrine homeostasis, thyroid function, and glucose metabolism. Zinc deficiency in the body can cause a decrease in the level of thyroid hormone secretion, which affects the body's normal metabolism and metabolic rate at rest (12). The results of this study are not in line with those found by Nishi et al., who reported abnormal zinc metabolism in patients with thyroid dysfunction (17). A study by Sinha et al. also reported a correlation between zinc deficiency and hyperthyroidism (16). Khanam reported that zinc deficiency can cause hypothyroidism (12).

A study conducted by Kiani et al. reported that in the melasma group, $37.8 \%$ of patients had thyroid dysfunction, compared to a control group with only $11.1 \%$ of participants having thyroid dysfunction (18). The mechanism by which thyroid hormones can affect melasma remains unclear. Pigment changes can occur in thyroid dysfunction, and hyperpigmentation abnormalities are reported to be related to hyperthyroidism. ACTH and melanocytestimulating hormone (MSH) can activate melanocortin receptors in melanocytes that induce melanogenesis.(2) A study by Kumre et al. reported that TSH levels were normal in 45 melasma patients $(65.8 \%)$, TSH levels were increased in 18 patients $(27.3 \%)$, and TSH levels were decreased in five patients (7.6\%), suggesting that hypothyroidism was associated with melasma (28). A study by Rostami Mogaddam et al. reported that $18.5 \%$ of melasma patients had thyroid dysfunction (29), whereas Achar et al. reported that as many as $6.4 \%$ of melasma patients had hypothyroidism (15).

\section{Conclusions}

There were no significant differences between serum zinc levels in the melasma and non-melasma groups with and without thyroid dysfunction. 


\section{References}

1. Rostami Mogaddam M, Safavi Ardabili N, Iranparvar Alamdari M, Maleki N, Aghabalaei Danesh M. Evaluation of the serum zinc level in adult patients with melasma: is there a relationship with serum zinc deficiency and melasma? J Cosmet Dermatol. 2018;17:417-22.

2. Çakmak SK, Özcan N, Kiliç A, Koparal S, Artüz F, Çakmak A, et al. Etiopathogenetic factors, thyroid functions and thyroid autoimmunity in melasma patients. Postep Dermatologii i Alergol. 2015;32:327-30.

3. Sarkar R, Arora P, Garg VK, Sonthalia S, Gokhale N. Melasma update. Indian Dermatol Online J. 2014;5:426-36.

4. Handel AC, Miot LDB, Miot HA. Melasma: a clinical and epidemiological review. An Bras Dermatol. 2014;89:771-82.

5. Gupta M, Mahajan VK, Mehta KS, Chauhan PS. Zinc therapy in dermatology: a review. Dermatol Res Pract. 2014;2014:1-11.

6. Salgueiro MJ, Weill R, Zubillaga M, Lysionek A, Caro R, Goldman C, et al. Zinc deficiency and growth. Biol Trace Elem Res. 2004;99:49-69.

7. Wessells KR, Brown KH. Estimating the global prevalence of zinc deficiency: results based on zinc availability in national food supplies and the prevalence of stunting. PloS One. 2012;7.

8. Galetti V, Mitchikpè CE, Kujinga P, Tossou F, Hounhouigan DJ, Zimmermann MB, et al. Rural Beninese children are at risk of zinc deficiency according to stunting prevalence and plasma zinc concentration but not dietary zinc intakes. J Nutr. 2016;146:114-23.

9. Prasetyo TJ, Hardinsyah H, Baliwati YF, Sukandar D. The application of probability method to estimate micronutrient deficiencies prevalence of Indonesian adults. Jurnal Gizi dan Pangan. 2018;13:17-26.

10. Yousefi A, Khoosani ZK, Forooshani SZ, Foorani N, Moini AM, Askandari Y. Is topical zinc effective in the treatment of melasma? A double-blind randomized comparative study. Am Soc Dermatologic Surg. 2014;40:33-7.

11. Arora M, Mahat RK, Kumar S, Mustafa I, Sah SP. Study of trace elements in patients of hypothyroidism with special reference to zinc and copper. Biomed J Sci Tech Res. 2018;6:1-5.

12. Khanam S. Impact of zinc on thyroid metabolism. J Diabetes Metab Disord Control. 2018;5:00134.

13. Gottschalk RW, Agim NG, Ortonne J. Reliability assessment and validation of the Melasma Area and Severity Index (MASI) and a new modified MASI scoring method. J Am Acad Dermatol. 2010;64:78-83.e2.

14. Rodrigues M, Ayala-Cortés AS, Rodríguez-Arámbula A, Hynan LS, Pandya AG. Interpretability of the modified melasma area and severity index (mMASI). JAMA Dermatol. 2016;152:1051-2.
15. Achar A, Rathi SK. Melasma: a clinico-epidemiological study of 312 cases. Indian J Dermatol. 2011;56:380-2.

16. Sinha S, Kar K, Dasgupta A, Basu S, Sen S. Correlation of serum zinc with TSH in hyperthyroidism. Asian J Med Sci. 2016;7:66-9.

17. Nishi Y, Kawate R, Usui T. Zinc metabolism in thyroid disease. Postgard Med J. 1980;56:833-7.

18. Kiani A, Ahmari M, Reza RFM. Association of melasma with thyroid disorders: a case control study. Iran J Dermatol. 2006;9:154-8.

19. Sarkar R, Gokhale N, Godse K, Ailawadi P, Arya L, Sarma N, et al. Medical management of melasma: a review with consensus recommendations by Indian Pigmentary Expert Group. Indian J Dermatol. 2017;62:558-577.

20. Sanchez NP, Pathak MA, Sato S, Fitzpatrick TB, Sanchez JL, Mihm MC. Melasma: A clinical, light microscopic, ultrastructural, and immunofluorescence study. J Am Acad Dermatol. 1981;4:698-710.

21. Pichardo R, Vallejos Q, Feldman SR, Schulz MR, Verma A, Quandt SA, et al. The prevalence of melasma and its association with quality of life in adult male Latino migrant workers. Int J Dermatol. 2009;48:22-6.

22. Sarkar R, Puri P, Jain RK, Singh A, Desai A. Melasma in men: a clinical, aetiological and histological study. J Eur Acad Dermatology Venereol. 2010;24:768-72.

23. Huang Y, Cai L, Zheng Y, Pan J, Li L, Zong L, et al. Association between lifestyle and thyroid dysfunction: a cross-sectional epidemiologic study in the She ethnic minority group of Fujian Province in China. BMC Endocr Disord. 2019;19:1-9.

24. Wiersinga WM. Clinical relevance of environmental factors in the pathogenesis of autoimmune thyroid disease. Endocrinol Metab. 2016;31:213-22.

25. Bagherani N, R Smoller B. An overview of zinc and its importance in dermatology-Part II: The association of zinc with some dermatologic disorders. Glob Dermatol. 2016;3:337-50.

26. Sharquie KE, Al-Mashhadani SA, Salman HA. Topical $10 \%$ zinc sulfate solution for treatment of melasma. Dermatol Surg. 2008;34:1346-9.

27. Iraji F, Tagmirriahi N, Gavidnia K. Comparison between the efficacy of $10 \%$ zinc sulfate solution with $4 \%$ hydroquinone cream on improvement of melasma. Adv Biomed Res. 2012;1:1-36.

28. Kumre K, Varma K, Sharma H, Singh U. Study of hormonal profile in female melasma patients in a tertiary care hospital. J Evol Med Dent Sci. 2016;5:1663-6.

29. Rostami Mogaddam M, Iranparvar Alamdari M, Maleki N, Safavi Ardabili N, Abedkouhi S. Evaluation of autoimmune thyroid disease in melasma. J Cosmet Dermatol. 2015;14:167-71.

30. Lowe NM, Fekete K, Decsi T. Methods of assessment of zinc status in humans: a systematic review. Am J Clin Nutr. 2009;89:2040-51. 